\title{
边境口岸城市蒙古族生态移民 语言文化适应研究
}

\section{Linguistic and Cultural Adaptation of Mongolian Ecological Immigrants in the Border City}

赵剑宏*

内蒙古大学外国语学院

呼和浩特 内蒙古 中国, 010021 4991521@163.com

\author{
Zhao Jianhong \\ Inner Mongolia University \\ School of Foreign Languages \\ Hohhot, Inner Mongolia, China 010021
}

本文以内蒙古二连浩特市蒙古族生态移民 社区为调查地, 根据行为适应、语言文化态度、 族际通婚和跨境婚姻等变量, 分析当前边境地 区少数民族生态移民的语言文化适应以及文化 心理、身份认同等问题。新时期边境地区的民 族工作, 要把发展作为解决问题的根本途径, 完善城镇社会保障体系, 提升民族教育和职业 培训质量, 加大文化惠民工程力度, 丰富边境 口岸城市的语言文化生活, 满足生态移民的精 神文化需求。恰当处理语言文化关系, 发挥语 言文化的固边作用, 有助于巩固和发展和谐的 民族关系。

[关键词］语言文化适应; 蒙古族; 生态移民; 口岸城市
This is a case study in Erenhot City, Inner Mongolia Autonomous Region on Mongolian ecological immigrants' linguistic and cultural adaptation as well as the cultural psychology and related identity issues according to the attitudes towards residence patterns, marriage, language, culture and other variables. Based on the data analysis, the study puts forward the suggestions of the current work with regard to ethnic groups. To solve the problems of the immigrants' adaptation, the vital method is the economic and social development, including improving the system of urban social security, raising the quality of ethnic education and vocational training, increasing the intensity of culture projects, and enriching the cultural life of border cities to satisfy the spiritual and cultural needs of ecological migration. Proper handling the relationship between language and culture makes a significant contribution to the consolidation and development of the

\footnotetext{
* [作者简介 $]$ 赵剑宏, 博士, 内蒙古大学外国语学院讲师。研究方向：社会语言学。

[基金项目] 本文为教育部人文社会科学重点研究基地重大项目 “中国边境地区语言文化安全调查一一 边境民族语言关系及语言生活研究”（11JJD850006）的阶段性成果。
} 
边境口岸城市蒙古族生态移民语言 140
Linguistic and Cultural Adaptation of Mongolian Ecological Immigrants in the Border City

harmonious ethnic relationship.

Key words: Linguistic and cultural adaptation; Mongolian; Ecological migrants; Border city.

民族关系是具有特定内涵的社会关系, 是民族发展过程中相关民族之间的 相互交往、联系和作用、影响的动态关系。我国是一个统一的多民族国家，正 确处理好社会主义的民族关系, 关系到国家的长治久安, 关系到祖国的统一、 繁荣与富强, 关系到社会主义现代化建设的成败。要实现中华民族伟大复兴的 中国梦，必须加强民族交往交流交融，了解典型地区民族关系发展的新动向， 掌握民族交往中反映出的新型社会问题。在全面建成小康社会的新时期，巩固 和发展平等团结互助和谐的社会主义民族关系, 必须了解和掌握城镇化进程中 典型地区民族问题的新动向。

中国边境口岸地区的少数民族人口数量多，相当一部分属于跨境民族，其 语言文化适应问题具有典型性。开展少数民族移民社区实证研究，掌握新移民 语言生活第一手资料, 可以把握语言文化国情的新趋势, 为构建和谐民族关系 和中华民族共同体意识的相关研究提供依据。本民族关系研究多选取特定变量, 依靠量化分析进行实证研究。文根据内蒙古二连浩特市生态移民社区的实地调 查，探讨蒙古族生态移民的语言文化适应以及文化心理、身份认同等问题，并 提出相应的对策建议。

\section{1. 研究背景}

美国社会学家米尔顿 - 戈登（Gordon，1964）提出了衡量民族关系的七 个指标: 文化融合、结构融合（社区、职场和公共场域的构成和交往）、通婚、 认同、民族包容性（没有民族偏见）、交往互动（没有民族歧视）和公民相似 性（没有价值观和权利冲突）。马戎等（1989）、王俊敏（1997）等人借鉴戈 登的理论框架和研究手段, 分别在赤峰、呼和浩特等内蒙古农牧区和城市开展 民族关系调查。梳理国内民族关系研究成果，不同学者从民族关系的内涵、影 响民族关系的主要因素以及如何调节民族关系等方面展开了研究。上世纪 90 年代，费孝通（1993）在内蒙古等民族地区调查后提出，在整个边区，人文生 态失调和自然生态失调同样值得注意。生态移民文化适应是移民研究的重要内 容，有研究认为文化适应是生态移民的 “最终目的”（百乐・司宝才仁、韩昭 庆, 2007), 少数民族生态移民语言文化适应也成为民族研究关注的重要问题。 近年来, 有学者指出, 只有保留相对稳定的牧民社区才能传承蒙古族语言文字 和民族文化（盖志毅，2009）。移民工程客观上加速了蒙古族传统文化体系的 整体性变迁, 包括显性的物质文化和隐性的制度文化和精神文化, 这种变迁并 
不是传统文化内涵的全部丧失, 而是传统因素和现代因素互渗、整合, 是文化 的重构过程（焦克源、王瑞娟、苏利那，2008）。徐黎丽（2005）提出，各民 族对其他民族风俗习惯的态度是构成并影响民族关系的因素, 民族关系的好坏 直接影响人们对风俗习惯的态度。本世纪初，边境地区跨境民族的国家认同、 民族认同和宗教意识发生变化，引发敏感的文化和社会问题，威胁到国家安全 利益。

少数民族地区边境口岸城市的民族关系具有典型性, 因其常与跨境民族问 题相结合。跨境民族是一个特殊的社会群体，分居于不同国家却有着共同的血 缘文化关系，以及共同的民族情感和认同感，国境线并未成为民族情感和民族 认同的分界线，但又具有不同的国家认同感。因此，其群体身份具有多元性。 以蒙古族为例，境内外的蒙古族保留了长期历史发展过程中形成的语言、风俗 习惯、民族文化心理和文化认同，但因所在国国情、自然和社会人文环境、交 往民族的不同，受到不同文化影响，形成了不同的发展特点和趋势。近年来， 随着中国社会经济发展和边境地区开放程度提高, 在边境复杂的外部诱因影响 下，跨境民族的国家认同、民族认同和宗教意识发生变化，成为敏感的文化和 政治问题，引发了一系列边疆社会问题，直接威胁国家安全利益。《国务院关 于进一步促进内蒙古经济社会又好又快发展的若干意见》明确指出，内蒙古是 我国北方重要的生态安全屏障。内蒙古自治区党委按照中央的要求, 着眼长远 发展, 明确发展定位，提出 “8337” 发展思路，建设我国北方重要的生态安全 屏障和祖国北疆安全稳定屏障, 打造我国向北开放的重要桥头堡和沿边开发开 放经济带。开展边境口岸城市蒙古族生态移民社区调查, 从语言文化适应的角 度探讨构建和谐民族关系的路径，有助于 “一带一路” 战略的顺利实施。

二连浩特市是中蒙边境最大的口岸城市, 1956 年建市, 为准地级计划单 列市，辖区面积 4015 平方公里，每年对蒙贸易额占我国对蒙贸易总额的 $70 \%$ 以上，是我国对欧贸易的重要陆路交通枢纽。在内蒙古向北开放的战略中，二 连浩特市是中蒙友好合作的 “桥头堡”，也是中俄、中欧交流的重要节点。在 加快推进 “向北开放” 的战略中，二连浩特的区位优势将转换为发展优势，同 时也是构筑牢固安全屏障的重点区域。

内蒙古生态移民始于上世纪末，主要包括沙化区、山区和草原退化区的生 态移民（初春霞、孟慧君，2005）。2001 年，二连浩特市隶属的锡林郭勒盟 提出 “围封转移” 战略，在草场退化沙化地区实施围封禁牧，通过减人、减畜 来减轻草场负担, 转变畜牧业生产经营方式。二连浩特市按照 “突出休牧、兼 顾禁牧、因地制宜、分步推进” 的原则，加快草原生态保护建设步伐，部分牧 民成为 “生态移民”。2007 年，内蒙古自治区将二连浩特市列为牧业禁止开 发区。二连浩特市在锡林街道办事处辖区内建设了牧民移民社区 (“星光小区”)。 截至 2009 年，市辖格日勒敖都苏木 198 户牧民签订了入住星光小区移民楼的 合同书，占禁牧转移户的 $90 \%$ 。转移牧民可以享受草场补偿，年人均补偿款从 2006 年的 3000 多元增加到 2013 年的 1 万余元。 


\section{2. 移民社区调查}

2010 年, 中央民族大学调研团队在二连浩特市蒙古族移民社区 “星光小 区” 开展语言使用和语言态度调查, 家庭语言使用以蒙古语为主, 普通话和汉 文的社会地位评价最高（王远新，2013a）。在借鉴相关研究和前期研究基础 上，笔者设计完成《内蒙古边境口岸地区居民调查问卷》，并于 2013 年 10 月在该社区开展入户调查, 调查形式为一对一问卷调查和访谈, 受访者 41 人, 完成有效问卷 41 份。

\section{1 受访者信息}

民族：受访者及其父辈、已婚受访者配偶及其子女均为蒙古族。

年龄：受访者最小 16 岁, 最大 75 岁, 平均年龄 35 岁（中位数 32 , 标准 差 14.729）。

表 1：受访者基本信息（ $\mathrm{N}=41 ）$

\begin{tabular}{|c|c|c|c|c|c|c|c|c|c|c|c|c|c|c|}
\hline \multirow[b]{2}{*}{$\begin{array}{l}\text { 类 } \\
\text { 别 }\end{array}$} & \multicolumn{2}{|c|}{ 性别 } & \multicolumn{2}{|c|}{ 婚姻 } & \multicolumn{2}{|c|}{ 子女 } & \multicolumn{4}{|c|}{ 迁入时间 } & \multicolumn{4}{|c|}{ 年龄 } \\
\hline & 男 & 女 & 已婚 & 未婚 & 有 & 无 & $\begin{array}{l}1 \text { 年 } \\
\text { 以下 }\end{array}$ & $\begin{array}{l}1-4 \\
\text { 年 }\end{array}$ & $\begin{array}{l}5-9 \\
\text { 年 }\end{array}$ & $\begin{array}{l}10 \text { 年 } \\
\text { 以上 }\end{array}$ & $\begin{array}{l}\text { 少年 } \\
\text { (16- } \\
19 \text { ) }\end{array}$ & \begin{tabular}{|l} 
青年 \\
$(20-$ \\
$39)$
\end{tabular} & $\begin{array}{l}\text { 中年 } \\
\text { (40- } \\
59)\end{array}$ & $\begin{array}{l}\text { 老年 } \\
\text { (60- } \\
75)\end{array}$ \\
\hline 数 & 20 & 21 & 31 & 10 & 25 & 16 & 6 & 13 & 15 & 7 & 5 & 23 & 9 & 4 \\
\hline$\%$ & 48.8 & 51.2 & 75.6 & 24.4 & 61.0 & 39.0 & 14.6 & 31.7 & 36.6 & 17.1 & 12.2 & 56.1 & 22.0 & 9.8 \\
\hline
\end{tabular}

职业类别: 牧民 (18 人, $43.9 \%)$ ，个体经营者 (9人， $22.0 \%)$ ，学生 (7 人， $17.1 \%)$ ，零时工 $(4$ 人， $9.8 \%)$ ，企业职工 (2人， $4.9 \%)$ ，公务员（1 人, $2.4 \%)$ 。

经济收入: 月平均收入 500 元以下为 1 人 (2.4\%)，500-1500 元，17人 $(41.5 \%) ， 1500-3000$ 元 8 人 $(19.5 \%) ， 3000-5000$ 元 5 人 (12. $2 \%) ， 5000$ 元以上 3 人 (7.3\%), 学生 7 人 (17.1\%)。结合职业分析, 除学生以外, 半 数以上移民在迁入地仅靠草场补贴为生。在有稳定收入来源的移民中, 个体经 商者比例最高, 主要经营民族工艺品、肉食品、民族服饰、民族餐馆等。调查 时, 社区内三成住户门窗紧锁, 部分住户门上贴有热力公司取暖费催缴通知单, 个别住户拖欠取暖费近万元。一位中年男性受访者说, 尽管牧业补贴不断提高, 但物价不断上涨，城市生活成本增加，生活水平没有明显提高。

教育背景: 中老年受访者的受教育程度较低; 青年学历明显高于前辈, 青 年组内初中学历受访者比例最高 $(43.5 \%)$ 。从教育类别看, 绝大多数受访者 接受了蒙古语授课为主加授汉语文的民族教育（简称 “蒙授”），仅个别受访 者接受了汉语授课的普通教育（简称 “汉授”）。调查显示，社区常住居民中 青年人占多数, 调查样本反映了这一现实。部分年轻人找不到工作, 在家中无 
所事事，甚至迷上奢博活动。接受高等教育的五名青年受访者中，艺术类专业 两人, 语言类专业两人, 职业技术专业一人, 调查时两名受访者尚未找到工作。

表 2: 学历及类型

\begin{tabular}{|c|c|c|c|c|c|c|c|}
\hline \multirow{2}{*}{\multicolumn{3}{|c|}{ 类别 }} & \multicolumn{5}{|c|}{ 年龄组 } \\
\hline & & & 少年组 & 青年组 & 中年组 & 老年组 & 合计 \\
\hline \multirow{12}{*}{$\begin{array}{l}\text { 受教育 } \\
\text { 程度 }\end{array}$} & \multirow{2}{*}{ 无 } & 人数 & 0 & 0 & 0 & 2 & 2 \\
\hline & & $\%$ & .0 & .0 & .0 & 50.0 & 4.9 \\
\hline & \multirow{2}{*}{ 小学 } & 人数 & 0 & 1 & 2 & 2 & 5 \\
\hline & & $\%$ & .0 & 4.3 & 22.2 & 50.0 & 12.2 \\
\hline & \multirow{2}{*}{ 初中 } & 人数 & 0 & 10 & 3 & 0 & 13 \\
\hline & & $\%$ & .0 & 43.5 & 33.3 & .0 & 31.7 \\
\hline & \multirow{2}{*}{ 高中/中专 } & 人数 & 5 & 7 & 4 & 0 & 16 \\
\hline & & $\%$ & 100.0 & 30.4 & 44.4 & .0 & 39.0 \\
\hline & \multirow{2}{*}{ 大专以上 } & 人数 & 0 & 5 & 0 & 0 & 5 \\
\hline & & $\%$ & .0 & 21.7 & .0 & .0 & 12.2 \\
\hline & \multirow{2}{*}{ 合计 } & 人数 & 5 & 23 & 9 & 4 & 41 \\
\hline & & $\%$ & 100.0 & 100.0 & 100.0 & 100.0 & 100.0 \\
\hline \multirow{8}{*}{$\begin{array}{l}\text { 受教育 } \\
\text { 类别 }\end{array}$} & \multirow{2}{*}{ 蒙授 } & 人数 & 4 & 23 & 9 & 2 & 38 \\
\hline & & $\%$ & 80.0 & 100.0 & 100.0 & 50.0 & 92.7 \\
\hline & \multirow{2}{*}{ 汉授 } & 人数 & 1 & 0 & 0 & 0 & 1 \\
\hline & & $\%$ & 20.0 & .0 & .0 & .0 & 2.4 \\
\hline & \multirow{2}{*}{ 无 } & 人数 & 0 & 0 & 0 & 2 & 2 \\
\hline & & $\%$ & .0 & .0 & .0 & 50.0 & 4.9 \\
\hline & \multirow{2}{*}{ 合计 } & 人数 & 5 & 23 & 9 & 4 & 41 \\
\hline & & $\%$ & 100.0 & 100.0 & 100.0 & 100.0 & 100.0 \\
\hline
\end{tabular}

21 名受访者的子女在上学, 其中 20 人 ( $95.2 \%)$ 的子女为蒙授教育, 1 人 (4.8\%) 的子女分别接受蒙授和汉授教育。关于子女教育模式选择， 39 人 （95.1\%）希望后代接受蒙授教育，1 人 (2.4\%) 选择汉授教育，1 人（2.4\%） 选择无法回答。数据说明, 移民子女与其父母的教育类型相似度高, 以蒙授为 主; 移民社区教育模式选择在近期不会发生显著变化, 但已出现移民子女上汉 族学校的情况。

\section{2 居住格局}

民族居住格局是指特定区域内不同民族在空间上的排列与组合情况。口岸 城市蒙古族移民社区是蒙古族相对集中的聚居地。通过调查受访者认为最理想 的生活地和居住格局，可以反映蒙古族移民居住格局的认同度。

调查中，除了迁出地和迁入地，在其他地区有过一年以上生活经历的受访 
边境口岸城市蒙古族生态移民语言 144
Linguistic and Cultural Adaptation of Mongolian Ecological Immigrants in the Border City

者 11 人 $(26.8 \%)$ 。

表 3: 理想的工作或生活地

\begin{tabular}{|c|c|c|c|c|c|c|}
\hline \multirow{2}{*}{\multicolumn{2}{|c|}{ 类别 }} & \multicolumn{5}{|c|}{ 年龄组 } \\
\hline & & \multirow{2}{*}{$\begin{array}{l}\text { 少年组 } \\
1\end{array}$} & \multirow{2}{*}{$\begin{array}{l}\frac{\text { 青年组 }}{5} \\
\end{array}$} & \multirow{2}{*}{$\begin{array}{l}\text { 中年组 } \\
\end{array}$} & \multirow{2}{*}{ 老年组 } & \multirow{2}{*}{$\begin{array}{l}\text { 合计 } \\
15\end{array}$} \\
\hline 原居 & 人数 & & & & & \\
\hline 住地 & $\%$ & 20.0 & 21.7 & 55.6 & 100.0 & 36.6 \\
\hline \multirow{2}{*}{$\begin{array}{l}\text { 现居 } \\
\text { 住地 }\end{array}$} & 人数 & 3 & 14 & 4 & 0 & 21 \\
\hline & $\%$ & 60.0 & 60.9 & 44.4 & .0 & 51.2 \\
\hline \multirow{2}{*}{$\begin{array}{l}\text { 无所 } \\
\text { 谓 }\end{array}$} & 人数 & 1 & 4 & 0 & 0 & 5 \\
\hline & $\%$ & 20.0 & 17.4 & .0 & .0 & 12.2 \\
\hline \multirow{2}{*}{ 合计 } & 人数 & 5 & 23 & 9 & 4 & 41 \\
\hline & $\%$ & 100.0 & 100.0 & 100.0 & 100.0 & 100.0 \\
\hline
\end{tabular}

理想的工作或生活地点调查项,没有人选择到内地或国外居住。数据表明, 半数蒙古族移民已经适应现居住地的生活, 但近四成移民仍不适应迁入地的城 市生活，而更喜欢牧区生活环境。全体移民的居住地选择倾向较为保守，并不 希望离开熟悉的生活环境。结合年龄分析, 青少年更喜欢现居住地, 中老年更 喜欢原居住地。蒙古族移民年龄越小，越能接受新的居住环境。

表 4：理想的居住环境

\begin{tabular}{|c|c|c|c|c|c|c|}
\hline \multirow{2}{*}{\multicolumn{2}{|c|}{ 类别 }} & \multicolumn{5}{|c|}{ 年龄组 } \\
\hline & & \multirow{2}{*}{ 少年组 } & \multirow{2}{*}{$\begin{array}{l}\text { 青年组 } \\
10\end{array}$} & \multirow{2}{*}{\begin{tabular}{|l} 
中年组 \\
5
\end{tabular}} & \multirow{2}{*}{$\begin{array}{l}\text { 老年组 } \\
2\end{array}$} & \multirow{2}{*}{$\frac{\text { 合计 }}{18}$} \\
\hline \multirow{2}{*}{ 同民族聚居 } & 人数 & & & & & \\
\hline & $\%$ & 20.0 & 43.5 & 55.6 & 50.0 & 43.9 \\
\hline \multirow{2}{*}{ 无所谓 } & 人数 & 4 & 12 & 4 & 2 & 22 \\
\hline & $\%$ & 80.0 & 52.2 & 44.4 & 50.0 & 53.7 \\
\hline \multirow{2}{*}{ 无法回答 } & 人数 & 0 & 1 & 0 & 0 & 1 \\
\hline & $\%$ & .0 & 4.3 & .0 & .0 & 2.4 \\
\hline \multirow{2}{*}{ 合计 } & 人数 & 5 & 23 & 9 & 4 & 41 \\
\hline & $\%$ & 100.0 & 100.0 & 100.0 & 100.0 & 100.0 \\
\hline
\end{tabular}

理想的居住格局调查数据表明,半数蒙古族移民的居住格局倾向较为宽容, 能够接纳不同民族杂居的环境。结合年龄分析，青少年比中老年的居住倾向更 宽容。

综上, 从居住格局倾向看, 蒙古族中老年移民的城市适应能力低于青少年。 年龄、受教育程度与居住格局倾向成正相关。 


\section{3 行为适应}

行为适应是社会融入能力的具体反映。移民在迁入地的人际交往范围和生 活习惯如饮食、衣着、休闲方式等行为的适应，体现其社会融入能力。

人际交往（朋友的民族）：蒙古族为主的为 23 人（56.1\%），汉族为主 2 人 $(4.9 \%)$ ，蒙古族和汉族一样多 16 人 (39\%)。

社交倾向（到政府部门办事常联系的工作人员）：蒙古族 8 人 (19.5\%)， 汉族 2 人 (4.9\%)，无倾向 26 人 (63.4\%)，无此情况 5 人 (12.2\%)。

饮食习惯（外出就餐类型）：蒙餐 13 人 $(31.7 \%)$ ，汉餐 1 人（2. $4 \% ）$ ， 无特定类型 26 人 $(63.4 \%)$ ，无此情况 1 人 (2.4\%)。

跨民族文化参与性（参与其他民族的聚会）：经常 8 人（19.5\%），有时 9 人 $(22 \%)$ ，偶尔 18 人 $(43.9 \%)$, 从不参加 6 人 $(14.6 \%)$ 。

交往难度（与其他民族交往的困难）：非常困难 2 人（4.9\%），有点困难 16 人 $(39 \%)$ ，交往自如 23 人（56.1\%）。

交往难度因素（与其他民族交往困难的原因，可多选）：选择语言因素的 12 人次 $(29.3 \%)$, 习惯 9 人次 $(22 \%)$ ，思维 6 人次 $(14.6 \%)$ ，宗教 2 人次 (4.9\%)。

综上，受访者的人际交往以本民族成员为主。半数移民的跨民族交往存在 困难, 影响因素主要是语言和习惯差异。在公共场域, 多数移民并无民族甄别 意识, $19.5 \%$ 的移民经常参与跨文化活动。

\section{4 语言文化态度}

\subsection{1 语言使用}

语言习得（小时候最先学会的语言）：蒙古语 38 人（92.7\%），蒙汉双语 3 人 $(7.3 \%)$ 。

语言掌握 (目前能使用交流的语言)：蒙古语单语 2 人 (4.9\%)，蒙汉双语 38 人 $(92.7 \%)$ ，蒙古语、汉语和外语（英语、韩语）1人（2. $4 \% ） 。$

语言使用一 (看电视) : 选择蒙古语节目 5 人 (12. $2 \%$ ), 汉语节目 3 人 (7. $3 \%) ，$ 蒙汉双语节目 33 人（80.5\%）。

语言使用二 (听广播)：选择蒙古语节目 10 人 (24. $4 \%$ ），汉语节目 2 人 (4. $9 \%)$ ，蒙汉双语节目 17 人 (41.4\%)，无此情况 12 人（29.3\%）。

语言使用三（上网）：蒙古文 4 人 $(9.8 \%)$ ，汉文 9 人（22\%），蒙汉双 文 14 人 (34.1\%)，无此情况 14 人 (34.1\%)。

语言使用数据显示, 绝大多数移民为蒙古语母语人; 大多数通过学校教育 或自学掌握蒙汉双语, 少数只掌握蒙古语, 个别大学生经常使用蒙古语、汉语 和外语。语言使用倾向表明, 多数人经常收听收看蒙古语和汉语节目, 收听广 播人数少于收看电视人数, 只收听蒙古语广播的人数高于只收看蒙古语电视的 
人数。网络使用人数最少, 只看汉文网站的人数比例高于收听收看汉语广播电 视的人数。数据说明, 民族语新媒体发展较缓慢, 仅仅依靠传统民族语媒体无 法满足移民的资讯需求。

\section{4.2 语言态度}

蒙古语评价: 有用 41 人（100\%）。

汉语评价: 有用为 38 人 $(92.7 \%)$, 没有用 1 人 (2. $4 \%)$, 无法回答 2 人 (4. $9 \%$ )。其中认为汉语没有用的受访者为 31 岁女性, 牧民, 初中文化程 度, 月收入较低。

蒙古语发展前景期望: 有很大发展为 31 人 ( $75.6 \%)$ ，在一定范围发展 5 人 $(12.2 \%)$ ，任其自然发展 4 人（9.8\%），无法回答 1 人（2.4\%）。

汉语发展前景期望：有很大发展为 29 人（ $70.7 \% ） ，$ 在一定范围发展 2 人 $(4.9 \%)$ ，任其自然发展 9 人 (22\%)，无法回答 1 人（2. $4 \% ） 。$

语言态度数据显示，移民对蒙古语和汉语的社会地位评价普遍较高，大多 数人对两种语言的发展前景持积极的态度。蒙古语的社会地位评价和发展前景 期望均略高于汉语。

\section{4.3 文化评价}

蒙古族文化了解程度：高 36 人（87.8\%），低 5 人（12.2\%）。

中华民族文化了解程度：高 21 人 (51.2\%)，低 20 人（48.8\%）。

对中华民族文化的兴趣：高 13 人 (31.7\%)，中 17 人（41.5\%），低 11 人 $(26.8 \%)$ 。兴趣较低的 11 人中, 少年组 1 人 $(20 \%)$, 青年组 8 人 $(34.7 \%)$, 中年组 1 人 (11. 1\%)，老年组 1 人 ( $25 \%)$ 。

蒙古族文化发展前景期望: 有很大发展 35 人（85.4\%），在一定范围发展 2 人 $(4.9 \%)$ ，任其自然发展 4 人 (9.8\%)。

中华民族文化发展前景期望: 有很大发展 29 人（70.7\%），在一定范围发 展 3 人 (7.3\%)，任其自然发展 8 人（19.5\%），无法回答 1 人（2.4\%）。

文化评价数据显示, 多数移民比较了解蒙古族文化, 对中华文化不感兴趣 的占 $26.8 \%$ 。民族文化认同度略高于中华文化认同度。青年移民的中华文化认 同度低于其他年龄组。

语言文字是民族文化的重要载体,生态移民对本民族语言文化有着强烈的 认同感，希望母语和本民族文化能够得到传承和发展。调研中，一位中年男性 受访者认为, 民族语言和文化非常重要, 蒙古族要吸取满族丢失本民族语言的 教训, 要先学好本民族语言, 再学习其他民族的语言。调研者在实地采访中感 受到, 青少年的汉语水平明显高于父辈，汉语沟通交流更自如。 
2.5 通婚态度

2.5. 1 族际通婚

41 名受访者中, 家庭成员中有通婚情况的 5 人 (12. $2 \%)$ ，均为蒙汉通婚。 通婚的涉他态度调查（表 5）显示， $75.6 \%$ 的受访者不反对族际通婚，老年反 对比例最高, 中年反对比例最低。

表 5: 对不同民族结婚的看法

\begin{tabular}{|c|c|c|c|c|c|c|}
\hline \multirow{2}{*}{\multicolumn{2}{|c|}{ 类别 }} & \multicolumn{5}{|c|}{ 年龄组 } \\
\hline & & \multirow{2}{*}{$\frac{\text { 少年组 }}{1}$} & \multirow{2}{*}{\begin{tabular}{|l|} 
青年组 \\
3
\end{tabular}} & \multirow{2}{*}{ 中年组 } & \multirow{2}{*}{\begin{tabular}{|l} 
老年组 \\
1
\end{tabular}} & \multirow{2}{*}{$\frac{\text { 合计 }}{5}$} \\
\hline 应当提 & 人数 & & & & & \\
\hline 倡 烈 & $\%$ & 20.0 & 13.0 & .0 & 25.0 & 12.2 \\
\hline \multirow{2}{*}{$\begin{array}{l}\text { 应当尊 } \\
\text { 重 }\end{array}$} & 人数 & 3 & 15 & 7 & 1 & 26 \\
\hline & $\%$ & 60.0 & 65.2 & 77.8 & 25.0 & 63.4 \\
\hline \multirow{2}{*}{ 不赞成 } & 人数 & 1 & 5 & 1 & 2 & 9 \\
\hline & $\%$ & 20.0 & 21.7 & 11.1 & 50.0 & 22.0 \\
\hline \multirow{2}{*}{ 无法回 } & 人数 & 0 & 0 & 1 & 0 & 1 \\
\hline & $\%$ & $.0 \%$ & .0 & 11.1 & .0 & 2.4 \\
\hline \multirow{2}{*}{ 合计 } & 人数 & 5 & 23 & 9 & 4 & 41 \\
\hline & $\%$ & 100.0 & 100.0 & 100.0 & 100.0 & 100.0 \\
\hline
\end{tabular}

通婚的涉己态度调查（表 6）显示， $73.2 \%$ 的受访者不排斥本人或子女与 其他民族通婚, 比涉他态度支持率低 $2.4 \%$; 青年反对比例最高, 老年涉己与 涉他态度的反对比例差异最大（25\%）。

表 6: 本人或对子女族际通婚的态度

\begin{tabular}{|c|c|c|c|c|c|c|}
\hline \multirow{2}{*}{\multicolumn{2}{|c|}{ 类别 }} & \multicolumn{5}{|c|}{ 年龄组 } \\
\hline & & \multirow{2}{*}{\begin{tabular}{|l} 
少年组 \\
1
\end{tabular}} & \multirow{2}{*}{$\begin{array}{l}\text { 青年组 } \\
2\end{array}$} & \multirow{2}{*}{$\begin{array}{l}\text { 中年组 } \\
0\end{array}$} & \multirow{2}{*}{\begin{tabular}{|l}
$\left.\right|^{\text {老年组 }}$ \\
1
\end{tabular}} & \multirow{2}{*}{\begin{tabular}{|l} 
合计 \\
4
\end{tabular}} \\
\hline \multirow{2}{*}{ 会 } & 人数 & & & & & \\
\hline & $\%$ & 20.0 & 8.7 & $\begin{array}{ll}.0 \\
\end{array}$ & 25.0 & 9.8 \\
\hline \multirow{2}{*}{ 无所谓 } & 人数 & 3 & 14 & 7 & 2 & 26 \\
\hline & $\%$ & 60.0 & 60.9 & 77.8 & 50.0 & 63.4 \\
\hline \multirow{2}{*}{ 不会 } & 人数 & 1 & 7 & 2 & 1 & 11 \\
\hline & $\%$ & 20.0 & 30.4 & 22.2 & 25.0 & 26.8 \\
\hline \multirow{2}{*}{ 合计 } & 人数 & 5 & 23 & 9 & 4 & 41 \\
\hline & $\%$ & 100.0 & 100.0 & 100.0 & 100.0 & 100.0 \\
\hline
\end{tabular}

\section{5 .2 跨境婚姻}

中蒙跨境婚姻调查中, 全体受访者没有家庭成员与蒙古国人结婚。中蒙跨 境婚姻的涉他态度调查（表 7）显示，63.4\%的受访者不反对跨境婚姻, 老年反 
边境口岸城市蒙古族生态移民语言 148 文化适应研究
Linguistic and Cultural Adaptation of Mongolian Ecological Immigrants in the Border City

对比例最高, 青年反对比例最低。跨境婚姻与族际通婚的涉他态度相比, 支持 率下降 $12.2 \%$; 青年反对比例差异最小 (4.3\%), 老年反对比例差异最大 (25\%)。

表 7：对中蒙跨境婚姻的看法

\begin{tabular}{|c|c|c|c|c|c|c|}
\hline \multirow{2}{*}{\multicolumn{2}{|c|}{ 类别 }} & \multicolumn{5}{|c|}{ 年龄组 } \\
\hline & & \multirow{2}{*}{ 少年组 } & \multirow{2}{*}{\begin{tabular}{|l|} 
青年组 \\
1
\end{tabular}} & \multirow{2}{*}{$\begin{array}{l}\text { 中年组 } \\
1\end{array}$} & \multirow{2}{*}{ 老年组 } & \multirow{2}{*}{ 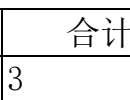 } \\
\hline \multirow{2}{*}{$\begin{array}{l}\text { 应当提 } \\
\text { 倡 }\end{array}$} & 人数 & & & & & \\
\hline & $\%$ & .0 & 4.3 & 11.1 & 25.0 & 7.3 \\
\hline \multirow{2}{*}{$\begin{array}{l}\text { 应当尊 } \\
\text { 重 }\end{array}$} & 人数 & 3 & 16 & 4 & 0 & 23 \\
\hline & $\%$ & 60.0 & 69.6 & 44.4 & .0 & 56.1 \\
\hline \multirow{2}{*}{ 不赞成 } & 人数 & 2 & 4 & 3 & 3 & 12 \\
\hline & $\%$ & 40.0 & 17.4 & 33.3 & 75.0 & 29.3 \\
\hline \multirow{2}{*}{$\begin{array}{l}\text { 无法回 } \\
\text { 答 }\end{array}$} & 人数 & 0 & 2 & 1 & 0 & 3 \\
\hline & $\%$ & .0 & 8.7 & 11.1 & .0 & 7.3 \\
\hline \multirow{2}{*}{ 合计 } & 人数 & 5 & 23 & 9 & 4 & 41 \\
\hline & $\%$ & 100.0 & 100.0 & 100.0 & 100.0 & 100.0 \\
\hline
\end{tabular}

中蒙跨境婚姻的涉己态度调查（表 8）显示，56.1\%的受访者不排斥本人 或子女与蒙古国人结婚, 青年反对比例最低; 中年反对比例最高, 与涉他态度 差异显著。跨境婚姻与族际通婚的涉己态度相比，支持率下降 $17.1 \%$ ，青年反 对比例差异最小 (4.4\%)，中年反对比例差异最大（33.4\%）。

表 8: 本人或对子女跨境结婚的态度

\begin{tabular}{|c|c|c|c|c|c|c|}
\hline \multirow{2}{*}{\multicolumn{2}{|c|}{ 类别 }} & \multicolumn{5}{|c|}{ 年龄组 } \\
\hline & & \multirow{2}{*}{$\begin{array}{l}\text { 少年组 } \\
0\end{array}$} & \multirow{2}{*}{$\begin{array}{l}\text { 青年组 } \\
2\end{array}$} & \multirow{2}{*}{0 中年组 } & \multirow{2}{*}{\begin{tabular}{|l} 
老年组 \\
1
\end{tabular}} & \multirow{2}{*}{3} \\
\hline \multirow{2}{*}{ 会 } & 人数 & & & & & \\
\hline & $\%$ & .0 & 8.7 & .0 & 25.0 & 7.3 \\
\hline \multirow{2}{*}{ 无所谓 } & 人数 & 3 & 13 & 3 & 1 & 20 \\
\hline & $\%$ & 60.0 & 56.5 & 33.3 & 25.0 & 48.8 \\
\hline \multirow{2}{*}{ 不会 } & 人数 & 2 & 8 & 5 & 2 & 17 \\
\hline & $\%$ & 40.0 & 34.8 & 55.6 & 50.0 & 41.5 \\
\hline \multirow{2}{*}{ 无法回答 } & 人数 & 0 & 0 & 1 & 0 & 1 \\
\hline & $\%$ & .0 & .0 & 11.1 & .0 & 2.4 \\
\hline \multirow{2}{*}{ 合计 } & 人数 & 5 & 23 & 9 & 4 & 41 \\
\hline & $\%$ & 100.0 & 100.0 & 100.0 & 100.0 & 100.0 \\
\hline
\end{tabular}

综上，移民的族际通婚和跨境婚姻态度较为宽容，对族际通婚的认同度高 于跨境婚姻。老年人婚姻观念最保守，族际通婚和跨境婚姻认同度均最低。中 年人族际通婚的认同度较高, 跨境婚姻的认同度较低。青年人跨境婚姻的认同 
度最高, 本人不愿或反对子女族际通婚的比例最高。调研中, 部分尚未结婚的 青年受访者明确表示不会与汉族结婚，但提出：“他们（蒙古国人）也是蒙古 族，结婚没问题。”一些中年受访者回答对子女婚姻的期待时，明确表示：“只 要脑子好（聪明），什么民族都可以”，“（与蒙古国人）讲不通道理，习惯 不一样，不能 (与他们) 结婚”。

族际通婚和跨境婚姻态度调查数据说明,边境口岸城市的民族认同呈现多 元化趋势。族际通婚和跨境婚姻态度的代际差异明显，青年的民族身份认同高 于前辈。一位正在内地上大学的受访者说, 近年国内蒙古族青年的民族认同感 越来越强, 一些人学习本民族语言、文化的积极性非常高。

\section{6 跨境文化认同}

文化接触（阅读或购买蒙古国图书杂志等）：经常 6 人（14.6\%），有时 6 人 $(14.6 \%)$ ，偶尔 4 人 $(9.8 \%)$ ，无此情况 25 人 $(61 \%) 。$

文化交流倾向一（引进蒙古国图书）：表示赞成的为 20 人（48.8\%），反 对 4 人 (9.8\%)，无所谓 11 人 (26.8\%)，无法回答 6 人（14.6\%）。

文化交流倾向二（引进蒙古国电视节目）：赞成 29 人（70.7\%），反对 2 人 $(4.9 \%)$ ，无所谓 8 人 (19.5\%)，无法回答 2 人 (4.9\%)。

文化交流倾向三（加强两国交往）：表示赞成的为 27 人（65.9\%），反对 1 人 (2. $4 \%)$ ，无所谓 8 人 (19.5\%)，无法回答 5 人 (12.2\%)。

跨境文化倾向调查表明, 由于文字书写体系差异, 多数移民不常阅读蒙古 国出版物, 个别青少年受访者借助工具书可以阅读蒙古国文字出版物, 并与蒙 古国朋友经常交流。对引进蒙古国书籍和影视节目的态度较积极。一位受访者 介绍, 蒙古国流行音乐和幽默戏剧的质量更高, 自己经常收看。调研中, 当地 许多商铺出售蒙古国音乐和幽默剧光盘。

\section{3. 边境口岸城市民族工作的对策建议}

2014 年，习近平在内蒙古考察时，阐述了民族地区改革发展稳定的理论 和实践问题, 明确提出 “守望相助”。做好边疆民族地区工作，要守好家门， 守好祖国边疆, 守好内蒙古少数民族美好的精神家园; 要跳出自然条件和地域 限制, 有宽广的世界眼光, 有大局意识; 要牢固树立平等团结互助和谐的思想, 共同守卫祖国边疆，共同创造美好生活。在民族地区城镇化进程中，要切实保 障少数民族的合法权益，满足生态移民的精神文化需求，丰富边境口岸城市的 语言文化生活。让城市更好地接纳少数民族群众, 让少数民族生态移民更好地 融入城市生活，是今后民族工作的重点。

一是加快边境口岸城市的经济社会发展, 把发展作为解决民族问题的根本 途径。生态移民进城后面临生活支出剧增、生产方式转型困难等问题。53.7\% 的受访者认为收入低是目前生活的主要问题。26.8\%的受访者建议解决因官僚 
边境口岸城市蒙古族生态移民语言

文化适应研究
Linguistic and Cultural Adaptation of Mongolian

Ecological Immigrants in the Border City

作风等导致的民生问题，如补贴发放不及时、住房产权拖延等。因此，应尽快 帮助少数民族生态移民脱贫致富，切实解决青年移民的就业问题，使移民进城 后能留得住、有事做、生活有改善; 重点关注移民社区突出的民生问题，加大 惠民工作力度，提高行政办事效率；建立和完善城镇社会保障体系，解决移民 住房、养老、教育、就业、医疗等基本问题, 为移民安定生活提供保障。

二是提升民族教育和职业培训质量，提高少数民族移民的综合素质, 增强 移民劳动力的就业适应能力。政府应加大投入力度，提升民族学校教学质量， 为牧区移民子女提供良好的母语为教学媒介语的基础教育, 同时为自愿接受汉 授教育的移民提供便利的就学途径。政府还应根据市场需求，加快发展职业技 术教育, 针对移民开展多方位、多层次技术培训, 实现教育培训与岗位需求对 接。边境口岸城市应加快职业培训基地建设, 开展汽车驾驶、机械维修、公共 服务等技能培训，帮助进城牧民掌握一种或多种职业技能，提高家庭收入。

三是加大文化惠民工程力度, 倡导文明健康的生活方式。城镇化进程使得 少数民族传统文化面临巨大挑战。少数民族移民社区应增添和改善公共文化基 础设施, 强化社区作为文化活动核心的凝聚力, 吸引更多人积极参与社区文化 活动, 抵制奢博等不健康的娱乐活动。引导少数民族生态移民尽快适应城市生 活, 扩大人际交往范围, 提升其在新居住地的安全感和归属感, 避免成为城市 生活的“边缘人”（王远新，2013b）。

四是在加强跨境民族经济文化交流与合作的同时,注意协调民族认同和国 家认同的关系。恰当处理语言文化关系，增强边境地区少数民族的国家认同感 和归属感, 特别是加强青少年爱国主义教育和中华民族共同体教育, 培养青少 年树立正确的国家观、民族观、宗教观、历史观和文化观，维护民族团结和边 疆安全与稳定。

内蒙古地处反分裂反渗透斗争前沿, 肩负着维护国家政治安全和边疆安宁 的重大政治责任, 切实加强意识形态工作, 确保社会大局稳定, 要坚持和发扬 各民族心连心、手拉手的传统，深入开展民族团结进步宣传教育。做好民族工 作要以做好民生基础工作为基础, 让各族人民群众共享改革发展成果, 营造平 安和谐的社会环境，将灿烂的民族文化继承好、传承好。在 “一带一路”建设 中, 发挥语言文化的固边作用, 增强跨境民族的国家认同感和归属感, 有助于 巩固和发展和谐的民族关系，增强中华民族的凝聚力。

\section{参考文献}

百乐・司宝才仁、韩昭庆, 2007 , 试论三江源生态移民的文化变迁 $[\mathrm{J}]$ 。复旦 学报（社会科学版）（3）：134-140。

初春霞、孟慧君，2005，内蒙古生态移民面临问题及对策思考 $[\mathrm{J}]$ 。北方经济 
(6) : $57-58$ 。

费孝通，1993，边区民族社会经济发展思考 $[\mathrm{J}]$ 。北京大学学报（哲学社会科 学版) (1) : 10-18。。

盖志毅, 2009 , 对内蒙古边境牧区生态移民的几点思考 [N]。内蒙古日报（汉） 理论版，7-19: 3。

焦克源、王瑞娟、苏利那，2008，蒙古族生态移民的文化变迁考察一一基于对 内蒙古孪井滩的调查 $[\mathrm{J}]$ 。前沿 (11) : 146-149。

马戎、潘乃谷，1989，居住形式、社会交往与蒙汉民族关系 $[\mathrm{J}]$ 。中国社会科 学 (3) : 179-192。

王俊敏, 1997, 呼和浩特市区的民族迁移与居住格局 $[J]$ 。西北民族研究 (2) : $7-28$ 。

王远新， 2013a，城市 “牧民社区” 的语言生活 $[\mathrm{J}]$ 。满语研究（1）：87-95。 王远新, 2013b，应当加强少数民族生态移民语言文化适应的调查研究 [A]。王 远新（编）, 语言田野调查实录（九） [C]。北京: 中央民族大学出版社, $1-22$ 。

徐黎丽，2005，论民族文化与民族关系的互动影响 $[\mathrm{J}]$. 西北师大学报（3）: 93-95。

Milton M. G.,1964, Assimilation in American Life: The Role of Race,

Religion and National Origins. New York: Oxford University Press. 